\title{
Milliunit per Gram
}

National Cancer Institute

\section{Source}

National Cancer Institute. Milliunit per Gram. NCI Thesaurus. Code C122215.

An arbitrary unit of substance content expressed in milliunit(s) per gram. 